\title{
Fate of lactadherin P47 during post-testicular maturation and capacitation of boar spermatozoa
}

\author{
A. M. Petrunkina, A. Läkamp, M. Gentzel, M. Ekhlasi-Hundrieser \\ and $\mathrm{E}$. Töpfer-Petersen* \\ Institute for Reproductive Medicine, School of Veterinary Medicine Hannover, Germany
}

\begin{abstract}
Polyclonal avian antibody was used partially to characterize the pig sperm lactadherin P47. P47 is a mosaic protein, composed of two epidermal growth factor (EGF)like domains and two $\mathrm{C} 1 / \mathrm{C} 2$ domains. $\mathrm{P} 47$ is homologous to the bovine mammary gland protein MGP 53/57 and mouse milk fat globule protein. Expression of P47 along the male genital tract and its localization on spermatozoa during post-testicular maturation and capacitation were studied. P47 was detected in the testis and in all parts of the epididymis by immunohistochemistry and by western blots of tissue extracts. By indirect immunocytochemistry, P47 was localized at the apical ridge of the sperm head in testicular, epididymal and ejaculated spermatozoa. The
\end{abstract}

fluorescence intensity progressed during sperm transit from caput to cauda epididymis, probably caused by the ongoing expression and subsequent accumulation of P47 on the sperm surface. During the time course of capacitation, $\mathrm{P} 47$ appears to be unmasked by the release of coating proteins and appears to migrate from the apical ridge onto the entire acrosomal region, showing an intensive fluorescence pattern after $3 \mathrm{~h}$ capacitation in vitro. The kinetics of signal changes during in vitro capacitation were different in epididymal and ejaculated spermatozoa, indicating accelerated capacitational plasma membrane destabilization in epididymal spermatozoa.

\section{Introduction}

Surface architecture evolves continuously during the lifetime of spermatozoa. Mammalian spermatozoa undergo a series of ultrastructural and biochemical changes when passing through the male and female genital tracts. Initial changes, collectively called 'epididymal sperm maturation', occur in spermatozoa during their passage through the epididymis and are characterized by extensive remodelling of the sperm surface. This process is accompanied by the association and integration of exogenous lipids and proteins, removal of associated proteins as well as alteration and migration of integral plasma membrane components (for review, see Cooper, 1992; Yanagimachi, 1994; Kirchhoff and Hale, 1996). At ejaculation caused by contact with secretions of the accessory sex glands, the sperm surface becomes complemented by proteins of seminal plasma (Yanagimachi, 1994; Töpfer-Petersen et al., 1998). This surface coat protects the sperm cell membrane from rapid destabilization, which initiates the series of functional changes leading to the acquisition of fertilizing ability, a process known as 'capacitation'. In the female reproductive tract of a number of mammalian species,

*Correspondence

Email: edda.toepfer-petersen@tiho-hannover.de the removal of decapacitation factors and the priming of sperm fertilizing ability takes place in the caudal region of the isthmus where spermatozoa are held back due to their binding to the epithelium. At about the time of ovulation, by initiating the capacitation sequence, spermatozoa detach from the epithelium and swim to the site of fertilization, thereby continuing the capacitation process (Hunter, 1996, 2001; Suarez, 1999; Töpfer-Petersen, 1999; Töpfer-Petersen et al., 2002). Part of the capacitation process is an ongoing remodelling of the sperm surface. The dynamics of protein migration from one surface subdomain to another or within a distinct domain during capacitation have been demonstrated for several proteins (Töpfer-Petersen et al., 1990a,b; Blobel et al., 1992). For the integral protein P86/5, capacitating conditions lead to protein aggregation and re-distribution in the peri-acrosomal region (TöpferPetersen et al., 1990a,b). The re-distribution of proteins is a general phenomenon, leading to building of protein-free domains which appear to be involved in fusion between plasma membrane and outer acrosomal membrane (Aguas and Pinto de Silva, 1989; TöpferPetersen et al., 1990a,b; Benhoff, 1993). After binding to the zona pellucida via a multimeric ligand-receptor system (Shur, 1998) and penetration of the spermatozoa through the extracellular matrix as the result of the acrosome reaction, further ligand-receptor interactions 
between the spermatozoa and the egg cell membranes are required for fusion of both gametes. Along the route of spermatozoa to fertilization, the surface coat and externally orientated integral plasma membrane components confer on spermatozoa the ability to participate in this interaction sequence. Therefore, the identification and functional characterization of spermsurface proteins are relevant for understanding the molecular basis of fertilization.

Several sperm-surface associated proteins that appear to participate in different steps of fertilization have been identified in a number of mammalian species (Töpfer-Petersen et al., 1995; Snell and White 1996; Töpfer-Petersen 1999). Ensslin et al. (1998) isolated a novel peripherally associated $47 \mathrm{kDa}$ protein of pig spermatozoa, P47, by affinity chromatography from solubilized sperm plasma membrane proteins bound to immobilized zona pellucida glycoproteins. P47 displays a mosaic structure with two $\mathrm{N}$-terminal epidermal growth factor (EGF)-like domains followed by two tandem repeats that are similar to the $\mathrm{C} 1$ and $\mathrm{C} 2$ domain of the blood clotting factors $\mathrm{V}$ and VIII. The second EGF-like domain contains an integrin-binding sequence, RGD, and the C2-like domain contains the putative phospholipid binding motif (Ensslin et al., 1998; Anderson et al., 2000; Mather, 2000; Peterson et al., 2001). The pig sperm protein is homologous to the lactadherins, major components of the milk fat globule membrane of the mammary gland (formerly known as bovine PAS 6/7 or MGP 53/57 and mouse MFG-E8; Larocca et al., 1991; Aoki et al., 1995; for review and recommended nomenclature, see Mather, 2000). Lactadherin P47 is expressed in the testis and mammary gland of pigs and has also been documented by RT-PCR and northern blotting in cow, mouse and human testis. The cDNA-derived sequences of testicular proteins show 60-100\% amino acid sequence identity (Ensslin et al., 1998). P47 has been localized at the apical ridge or at the entire acrosomal region in testicular spermatozoa as well as in spermatozoa of different functional states (Ensslin et al., 1998). The authors of the present study suggest that this protein may be masked or unmasked during post-testicular maturation and capacitation, and this might be a part of maturation or capacitation-induced membrane remodelling. However, no quantification of patterns or kinetic studies characterizing the rates of changes on the sperm surface are known to support this hypothesis.

Although the transcription of P47 in the testis and epididymis has been recently reported (Ensslin et al., 1998), the present study used immunological approaches to assess the expression of P47 in tissues and extracts of the male reproductive tract and to describe the distribution of different P47 localization patterns and their changes during maturation and capacitation. Among the questions addressed in this study were: (1) Is P47 synthesized and secreted in the testis and in the epididymis?; (2) Do the epididymal secretions contribute to P47 distribution on spermatozoa?; and (3) Are there considerable individual differences between the location and content of P47 of epididymal or ejaculated spermatozoa and their kinetic changes during capacitation?

\section{Materials and Methods}

\section{Chemicals and media}

Unless otherwise stated, chemicals were obtained from Merck (Darmstadt), Roth (Karlsruhe) and Sigma Chemical Company (Steinheim) and were of suitably high purity. Enzymes were purchased from Roche Molecular Biochemicals, Mannheim (formerly Boehringer Mannheim) and the secondary antibodies Cy3conjugated anti-chicken IgY from goat and anti-chicken IgY-alkaline phosphatase from goat were obtained from Dianova (Hamburg).

A complete bicarbonate Tyrode's balanced salt solution $\left(\mathrm{pH} 7.4,300 \mathrm{mOsm} \mathrm{kg}{ }^{-1}\right)$ consisting of $96 \mathrm{mmol}$ $\mathrm{NaClI}^{-1}, \quad 3.1 \mathrm{mmol} \mathrm{KClI}^{-1}, \quad 5 \mathrm{mmol}$ glucose $\mathrm{I}^{-1}$, $0.4 \mathrm{mmol} \mathrm{MgSO}_{4} \mathrm{I}^{-1}, 15 \mathrm{mmol} \mathrm{NaHCO}_{3} \mathrm{I}^{-1}, 2 \mathrm{mmol}$ $\mathrm{CaCl}_{2} \mathrm{I}^{-1}, 0.3 \mathrm{mmol} \mathrm{NaH}_{2} \mathrm{PO}_{4} \mathrm{I}^{-1}, 1 \mathrm{mmol}$ sodium pyruvate $\mathrm{I}^{-1}, 21.6 \mathrm{mmol}$ sodium lactate $\mathrm{I}^{-1}, 3 \mathrm{mg}$ BSA ml ${ }^{-1}$ and $20 \mathrm{mmol}^{-1}$ Hepes $\mathrm{I}^{-1}, \mathrm{pH} 7.6$ (Tyrode's medium; Harrison et al., 1993) was used after equilibration at $39^{\circ} \mathrm{C}, 5 \% \mathrm{CO}_{2}$ for $1 \mathrm{~h}$ for sperm capacitation. Swim-up buffer consisted of $95 \mathrm{mmol}$ $\mathrm{NaClI}^{-1}, 5 \mathrm{mmol}$ glucose $\mathrm{I}^{-1}, 60 \mathrm{mmol}$ saccharose $\mathrm{I}^{-1}$, $1 \mathrm{mmol} \quad \mathrm{MgCl}_{2} \mathrm{I}^{-1}, 1.5 \mathrm{mmol} \mathrm{CaCl}_{2} \mathrm{I}^{-1}, 1 \mathrm{mmol}$ $\mathrm{K}_{2} \mathrm{HPO}_{4} \mathrm{I}^{-1}, 5 \mathrm{mmol}$ sodium pyruvate $\mathrm{I}^{-1}, 0.5 \%$ BSA and $20 \mathrm{mmol}^{2}$ Hepes $\mathrm{I}^{-1}\left(\mathrm{pH} 7.4,290 \mathrm{mOsm} \mathrm{kg}^{-1}\right)$. All media were passed through a $0.2 \mu \mathrm{m}$ single use filter unit (Minisart Sartorius, Göttingen) after preparation. TBS was composed of $50 \mathrm{mmol}$ Tris- $\mathrm{HClI}^{-1}, \mathrm{pH} 7.4$, and $150 \mathrm{mmol} \mathrm{NaCll}^{-1}$.

\section{Isolation of bovine milk protein MGP and preparation of antibody}

Bovine milk fat globule membrane protein (MGP) was isolated essentially as described by Aoki et al. (1994). Briefly, fresh bovine milk was skimmed by centrifugation at $4000 \mathrm{~g}$ for $15 \mathrm{~min}$. The raw cream was washed three times with water to remove adhering skimmed milk components. The washed cream was frozen at $-80^{\circ} \mathrm{C}$ for $1 \mathrm{~h}$, thawed and stirred for $1 \mathrm{~h}$ at $40^{\circ} \mathrm{C}$. After centrifugation $(5000 \mathrm{~g}, 20 \mathrm{~min}$ at room temperature) the MGP-enriched fraction was recovered in the middle phase of the tube. After dialysis for $24 \mathrm{~h}$ at $4^{\circ} \mathrm{C}$ against distilled water, the protein fraction was subjected to gel filtration on a Superose 12 HR10/30 column (Amersham Pharmacia, Uppsala) in $20 \mathrm{mmol}$ Tris- $\mathrm{HClI}^{-1}, \mathrm{pH} 7.4$, containing $150 \mathrm{mmol} \mathrm{NaClI}^{-1}$ and $1 \%(\mathrm{w} / \mathrm{v})$ CHAPS 
(3-[(3-cholamidopropy)dimethylammonio]-1 propanesulfonate; Sigma). The eluate was monitored by SDSPAGE. Fractions containing only the typical double band at 53/57 kDa were collected, dialysed and lyophilized. Identical MGP proteins were isolated from pig, horse and human milk.

Before immunization, bovine MGP 53/57 (300 $\mathrm{g} \mathrm{m} \mathrm{ml}^{-1}$ in PBS or $1 \%(\mathrm{w} / \mathrm{v})$ CHAPS) was treated with $\mathrm{N}$-glycosidase-F (3.5 U), O-glycosidase ( $1 \mathrm{U}$ ) and neuraminidase $(2 \mathrm{U})$ for 4 days at $37^{\circ} \mathrm{C}$ to remove most of the glycan chains. Deglycosylation was monitored by SDSPAGE. After digestion, MGP 53/57 was separated from glycans on a NAP-10 column (Amersham Pharmacia) in $1 \%(\mathrm{w} / \mathrm{v})$ CHAPS or PBS. The polyclonal antibody was generated by immunizing a pathogen-free cockerel with the purified and partially deglycosylated MGP 53/57. The antigen $(104 \mu \mathrm{g} ; 1.5 \mathrm{ml})$ was emulsified with Freund's complete adjuvant (Difco, Detroit, MI) and injected into several subcutaneous sites. A second immunization (104 $\mu \mathrm{g} ; 1.5 \mathrm{ml}$ ) was performed 4 weeks later. Blood was collected approximately 14 days after the second immunization. Pre-immune serum was collected about three weeks before the first immunization. Antibody was designated as anti-BT (Bos taurus) MGP 53/57. Specificity and crossreactivity were tested by SDS-PAGE and western blot analysis (see below).

\section{Sperm preparation}

Ejaculates were collected from healthy fertile boars from the Institute's colony and used within $30 \mathrm{~min}$. Estimation of sperm quality including evaluation of sperm concentration, sperm motility and assessment of the morphologically abnormal forms were performed as described by Petrunkina et al. (2001), according to the classification of Krause (1966). Sperm acrosomal status was evaluated by phase-contrast microscopy. Motile spermatozoa were selected by the swim-up procedure (for details see Petrunkina et al., 2001). For capacitation, sperm pellets $\left(5 \times 10^{7}\right.$ cells $\left.\mathrm{ml}^{-1}\right)$ were re-suspended with Tyrode's medium and incubated for $3 \mathrm{~h}$ at $39^{\circ} \mathrm{C}$ in $5 \% \mathrm{CO}_{2}$. The capacitation rates of spermatozoa were indirectly tested by inducing the acrosome reaction with lysophosphatidylcholin (LPC). Spermatozoa were incubated in Tyrode's medium for $3 \mathrm{~h}$, and then centrifuged ( $5 \mathrm{~min}, 300 \mathrm{~g}$ ). The pellets were resuspended in PBS containing 1\% goat serum and LPC $\left(10 \mu \mathrm{l}\right.$ of the stock solution $10 \mu \mathrm{g} \mathrm{ml}^{-1}$ in PBS), and incubated for $10 \mathrm{~min}$ before testing by indirect immunofluorescence.

Spermatozoa were flushed from testis and epididymal spermatozoa were collected from the caput, corpus and caudal region of the epididymis in PBS immediately after castration. Spermatozoa were diluted and washed three times in PBS (300 g, $5 \mathrm{~min}, 25^{\circ} \mathrm{C}$ ). Spermatozoa collected from the caudal region were incubated in Tyrode's medium as described above, for capacitation.
Sperm motility was estimated (cauda and ejaculated spermatozoa) and only spermatozoa meeting normozoospermic criteria were used for the following experiments. Treated and untreated spermatozoa were then prepared for microscopical investigation or were used for extraction as described below.

\section{Preparation of tissue and sperm extracts}

Tissue samples from the testis, caput, corpus and cauda epididymides, bulbourethral gland, prostate gland, seminal vesicle, liver and salivary gland were used. The tissue samples were cut with scissors and homogenized in extraction buffer (TBS, pH 7.5; 2 mmol benzamidin $\mathrm{I}^{-1} ; 1 \mathrm{mmol}$ phenylmethylsulphonyl fluoride (PMSF) $\mathrm{I}^{-1}$; and $1 \mathrm{mmol}^{\mathrm{EDTA}} \mathrm{I}^{-1}$ ) with an Ultraturrax (Jahnke and Kunkel, Staufen). After centrifugation for $20 \mathrm{~min}\left(13000 \mathrm{~g}\right.$ at $\left.4^{\circ} \mathrm{C}\right)$, the supernatants were collected as TBS extracts. The pellets were re-suspended in extraction buffer containing $1 \%(\mathrm{w} / \mathrm{v})$ CHAPS. After shaking for $2 \mathrm{~h}$ at $4{ }^{\circ} \mathrm{C}$ the samples were centrifuged at $13000 \mathrm{~g}$ for $20 \mathrm{~min}$. The supernatants were termed detergent extracts.

Boar sperm membranes were prepared from washed ejaculated spermatozoa using the nitrogen cavitation or centrifugation method and then solubilized as described by Ensslin et al. (1995).

Spermatozoa from caput, corpus and cauda epididymides and spermatozoa treated for capacitation were extracted in TBS, pH 7.5 (supplemented with $2 \mathrm{mmol}$ benzamidin $\mathrm{I}^{-1} ; 1 \mathrm{mmol} \mathrm{PMSFI}^{-1} ; 10 \mathrm{mmol}$ EDTA $^{-1}$; and $\left.1 \%(\mathrm{w} / \mathrm{v}) \mathrm{CHAPS}\right)$, for $2 \mathrm{~h}$ at $4{ }^{\circ} \mathrm{C}$. Supernatants were collected after centrifugation $(13000 \mathrm{~g}$ for $20 \mathrm{~min}$ at $4^{\circ} \mathrm{C}$ ) and stored at $-20^{\circ} \mathrm{C}$ until use.

\section{Sodium dodecyl sulphate-gel electrophoresis and western blot analysis}

Samples (15 $\mu$ g total protein per lane) of purified bovine and pig MGP 53/57, tissue and sperm extracts were subjected to sodium dodecyl sulphate (SDS) gel electrophoresis on $12.5 \%(\mathrm{w} / \mathrm{v})$ acrylamide gels using a discontinuous buffer system according to Laemmli (1970). Proteins were transferred to PVDF membranes (Roche) using a semi-dry system (buffer composition: $39 \mathrm{mmol}_{\text {glycine }}{ }^{-1} ; 48 \mathrm{mmol}$ Tris base $\mathrm{I}^{-1} ; 0.0375 \%$ $(\mathrm{w} / \mathrm{v})$ SDS; and $20 \%$ (v/v) methanol; $1 \mathrm{~mA} \mathrm{~cm}^{-2}$ for $2 \mathrm{~h}$ at room temperature). The membranes were incubated overnight at $4{ }^{\circ} \mathrm{C}$ with $10 \%(\mathrm{w} / \mathrm{v})$ blocking reagent (Roche) dissolved in TBS. Strips were then sequentially incubated with anti-BT MGP 53/57 (1: 4000, $\left.1 \mathrm{~h}, 25^{\circ} \mathrm{C}\right)$ and alkaline phosphatase-conjugated chicken antibody $(1: 5000,1 \mathrm{~h}$ at $25^{\circ} \mathrm{C}$ ) in TBS containing $1 \%$ blocking reagent. Each incubation was followed by three washing steps in TBS containing $0.3 \%$ Tween 20 and two additional washing steps in buffer $\left(0.1\right.$ mol Tris- $\mathrm{HCl}^{-1}, \mathrm{pH} 9.5$; and $0.1 \mathrm{~mol}$ $\mathrm{NaClI}^{-1}$ ) before the development of immunoreaction 


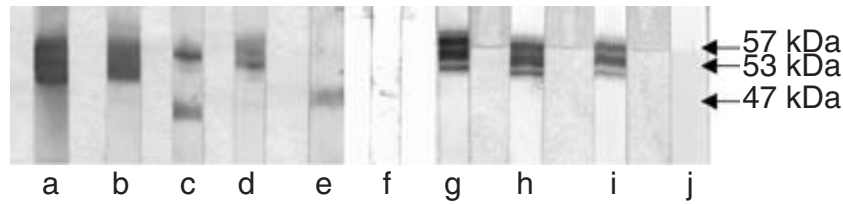

Fig. 1. Specificity and crossreactivity of antibody BT MGP 53/57 in the male genital tract in pigs. (a) Cow MGP; (b) pig MGP; (c) human MGP; (d) horse MGP; and (e) pig sperm membrane. (f) Inhibition of immunoreactivity of $47 \mathrm{kDa}$ band of sperm membranes by pre-incubation of antibody BT MGP 53/57 with isolated MGP 53/57. (g-j) Cow MGP with antibody BT MGP 53/57 in different concentrations: (g) $1: 1000$; (h) $1: 2000$; (i) $1: 4000$; and (j) $1: 8000$.

(30-60 min) with nitro blue tetrazolium-5-bromo-4chloro-3-indolyl phosphate (NBT/BCIP) used according to the manufacturer's recommendations (Roche). The reaction was stopped by washing with distilled water for at least $5 \mathrm{~min}$ and the strips were then air-dried and photographed. The first antibody (anti-BT MGP 53/57) was pre-incubated for 30 min with purified MGP 53/57 $\left(15 \mu \mathrm{g} \mathrm{ml}^{-1}\right.$ antibody dilutation) before use or replaced by the pre-immune serum at the same conditions to control the specificity. The $47 \mathrm{kDa}$ band was identified by $\mathrm{N}$-terminal analysis as described by Ensslin et al. (1995).

\section{Immunohistochemistry}

Tissues collected from testis, caput, corpus and cauda epididymides from slaughtered boars as well as liver and salivary gland as control tissues were used for immunohistochemical studies. Tissue samples (approximately $10 \mathrm{~mm} \times 10 \mathrm{~mm} \times 5 \mathrm{~mm}$ ) were fixed for $24-48 \mathrm{~h}$ in $4 \%$ formaldehyde in PBS. After fixation, tissues were washed with running water for $6-8 \mathrm{~h}$ and $70 \%$ ethanol for $24 \mathrm{~h}$. The preparations were dehydrated with increasing ethanol concentrations (70-100\%) followed by acetic acid- $N$-butylester (ENBE; Roth), and embedded in paraffin wax. Sections (about $7 \mu \mathrm{m}$ ) were mounted on poly-lysin coated slides, de-paraffinized and rehydrated in decreasing ethanol concentrations $(3 \times 5 \mathrm{~min}$ in xylol, $5 \mathrm{~min}$ in $100 \%$ ethanol, $2 \mathrm{~min}$ in $96 \%$ ethanol and $30 \mathrm{~min}$ in $85 \%$ ethanol and $3 \times 5 \mathrm{~min}$ in PBS). The nonspecific binding was blocked by incubation with $10 \%$ goat serum in $\mathrm{PBS}\left(30 \mathrm{~min}, 37^{\circ} \mathrm{C}\right)$, followed by incubation with the primary antibody (anti-BT MGP $53 / 57,1: 400(\mathrm{v} / \mathrm{v})$ in $\left.\mathrm{PBS}, 1 \mathrm{~h}, 37^{\circ} \mathrm{C}\right)$. After $3 \times 5 \mathrm{~min}$ washing in PBS, the samples were incubated with alkaline phosphatase-conjugated anti-chicken IgY from goat $\left(1: 50\right.$ in PBS; $\left.1 \mathrm{~h}, 37^{\circ} \mathrm{C}\right)$. Samples were then washed in PBS $(3 \times 5 \mathrm{~min})$ and stained with NBT/BCIP (Roche) according to the manufacturer's recommendation. The reaction was stopped with distilled water, and the samples mounted with Kaiser's glyceringelatine (Merck). As a control, the successive sections were probed with the alkaline phosphatase-conjugated anti-chicken IgY from goat $\left(1: 50\right.$ in $\left.\mathrm{PBS} ; 1 \mathrm{~h}, 37^{\circ} \mathrm{C}\right)$ or with anti-BT
MGP 53/57 pre-incubated with MGP 53/57 (15 $\mu \mathrm{g} \mathrm{m}^{-1}$ antibody dilution).

The preparations were studied under a phase-contrast Axioskop microscope (Zeiss, Oberkochen) at $\times 200$ and $\times 400$ magnification.

\section{Immunofluorescence microscopy}

Sperm suspensions $\left(10^{7}\right.$ cells $\left.\mathrm{ml}^{-1}\right)$ were smeared on slides, air-dried and fixed in $2 \%$ paraformaldehyde and $0.2 \%$ glutaraldehyde in PBS for $10 \mathrm{~min}$. The reaction was stopped with $0.1 \%$ glycine in PBS for $3 \mathrm{~min}$. After $2 \times 5$ min washing in PBS and $2 \times 5$ min washing in distilled water, the preparations were blocked with $20 \%$ goat serum in PBS in a wet chamber at $4^{\circ} \mathrm{C}$ overnight. The smears were then sequentially incubated with the primary antibody (anti-BT MGP 53/57, 1:500 in PBS containing $1 \%$ goat serum, $60 \mathrm{~min}, 37^{\circ} \mathrm{C}$ ) and $\mathrm{Cy} 3-$ conjugated anti-chicken IgY from goat diluted to 1:400 in PBS containing $1 \%$ goat serum. Each incubation was followed by washing $(3 \times 10 \mathrm{~min}$ in PBS) and two additional washing steps in PBS containing $0.1 \%$ TritonX100 before mounting the smears with glycerol-PBS $(9: 1)$. The primary antibody was replaced by preimmune serum or by $1 \%$ goat serum in PBS as a control.

The fluorescent slides were examined under an Axioscop microscope equipped with epifluorescence optics (Zeiss) using a $565 \mathrm{~nm}$ filter (magnification $\times 1000$ ). At least 100 cells were evaluated.

Alternatively, P47 was immunolocalized in live spermatozoa. Ejaculated sperm suspensions $\left(10^{7}\right.$ cells $\left.\mathrm{ml}^{-1}\right)$ were incubated with anti-BT MPG 53/57 (1:500 in PBS containing $1 \%$ goat serum) for $20 \mathrm{~min}$ at $37^{\circ} \mathrm{C}$. Sperm suspensions were then gently washed and incubated with Cy3-conjugated anti-chicken IgY $(1: 400$ in PBS and $1 \%$ goat serum) for $15 \mathrm{~min}$ at $37^{\circ} \mathrm{C}$. As propidium iodide was not suitable for double staining, the samples were stained with Hoechst $33258\left(5 \mu \mathrm{g} \mathrm{ml}^{-1}\right)$ for $5 \mathrm{~min}$. Specimens were directly viewed on a Zeiss Axioscop microscope under fluorescence and phasecontrast illumination, using a $565 \mathrm{~nm}$ excitation filter to view Cy3-fluorescence, and $365 \mathrm{~nm}$ excitation filter to view Hoechst staining. For testing P47 distribution in dead cells, spermatozoa were permeabilized with digitonin $\left(25 \mu \mathrm{g} \mathrm{ml}^{-1}\right)$ before immunoreaction.

Parallel to the determination of the percentage of dead cells using Hoechst dye, the percentage of dead cells in digitonin-treated and untreated sperm suspensions from the same ejaculate was determined using propidium iodide staining. Propidium iodide staining was performed essentially as described by Harrison and Vickers (1990). Briefly, $10 \mu \mathrm{l}$ propidium iodide stock solution $\left(0.5 \mathrm{mg} \mathrm{ml}^{-1}\right)$ was added to $1 \mathrm{ml}$ sperm suspension and incubated for $5 \mathrm{~min}$. The percentage of stained cells (membrane defect) was then determined by counting. 

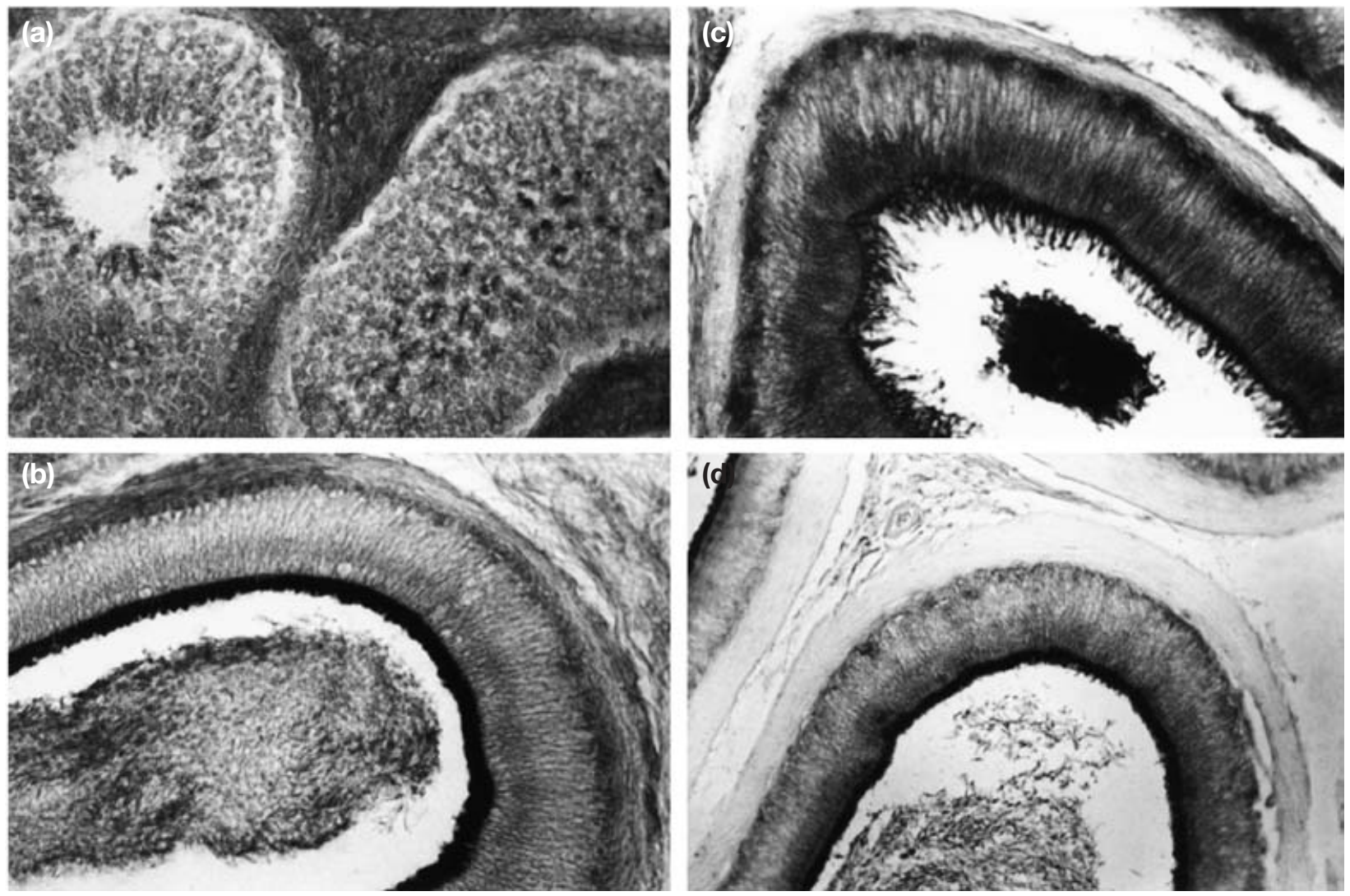

Fig. 2. Immunohistochemical localization of pig lactadherin P47 with antibody BT MGP 53/57 in tissues of the male genital tract of the pig. (a) Testis; (b) caput; (c) corpus; and (d) cauda epididymides. The reaction in control experiments (antibody replaced by PBS or goat serum, or inhibited by pre-incubation with purified MGP 53/57) was abolished or markedly reduced.

\section{Analysis of data}

Data were analysed using Excel software and the statistics software package SAS (Version 7; SAS Institute Inc., Cary, NC). ANOVA was performed to analyse the influence of sperm origin (ejaculated or epididymal) and time of incubation in capacitation medium. Nonlinear and linear modelling were performed and the corresponding model functions compared to describe the changes in kinetics of fluorescence signal shift during capacitation treatment. The rates of changes were compared using first derivatives of the model functions. Unless otherwise stated, data are presented as the mean \pm SEM. Differences were considered to be significant if the calculated probability that they would occur by chance was less than $5 \%(P<0.05)$.

\section{Results}

\section{Expression of P47 in the male genital tract}

Antibodies raised in chicken against bovine MGP 53/57 were shown to crossreact with a comparable crossreactivity with MGP proteins isolated from cow, pig, horse and human milk, and sperm membrane protein P47 in western blot analysis (Fig. 1). Positive reactions were observed only in late germ cells in the testis, indicating that P47 is already expressed in spermatids and differentiated spermatozoa (Fig. 2a). In contrast, the epithelial cells and the stereocilia in the caput and corpus epididymides showed strong immunoreaction (Fig. 2b,c). Signal intensity decreased in the cauda epididymidis (Fig. 2d) and was absent in the ductus deferens, seminal vesicle and prostate gland (data not shown). Concomitantly, spermatozoa clustered in the lumen showed immunoreaction with a decreasing signal intensity from the caput to cauda epididymides. Liver and salivary gland were completely negative (not shown). Pre-absorbed primary antibody and secondary antibody alone showed essentially no reaction, indicating the specificity of the antibody. In agreement with these findings, immunoreactive bands at $47 \mathrm{kDa}$ were detected in the detergent extracts of the epididymal tissues of each region after SDS-PAGE and western blotting (Fig. 3, lane $b, c, d)$. The signal in the testicular tissue extract was missing or very faint (Fig. 3, lane a), corresponding to the immunohistochemical results that P47 is expressed only in late germ cells. An immunoreactive band of a similar molecular weight to that of P47 was observed in the seminal vesicle and liver. The results were identical for all boars tested ( $n=3$; Table 1$)$. 


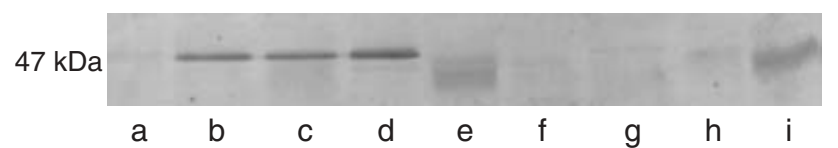

Fig. 3. Western blot analysis of CHAPS extracts of pig tissues. (a) Testis (b) caput epididymidis; (c) corpus epididymidis; (d) cauda epididymidis; (e) seminal vesicle; (f) prostate gland; (g) bulbourethral gland; (h) salivary gland; and (i) liver.

Table 1. Distribution of immunohistochemical reaction products against lactadherin P47 in tissues of the male genital tract in pigs

\begin{tabular}{llc}
\hline Tissue & \multicolumn{1}{c}{ Stained cells } & Staining intensity \\
\hline Testis & Spermatid/spermatozoa & + \\
Caput epididymidis & Epithelial cells/stereocilia & ++ \\
& Spermatozoa & +++ \\
Corpus epididymidis & Epithelial cells/stereocilia & +++ \\
& Spermatozoa & ++ \\
Cauda epididymidis & Epithelial cells/stereocilia & ++ \\
& Spermatozoa & ++ \\
Ductus vas deferens & Spermatozoa & + \\
Liver & - & - \\
Salivatory gland & - & - \\
\hline
\end{tabular}

+ faint intensity; ++ medium intensity; +++ high intensity; - no staining.

\section{Immunolocalization of P47 on epididymal and ejaculated spermatozoa}

Indirect immunofluorescence microscopy using the anti-MGP 53/57 antibody was used to assess the topology of P47 on spermatozoa at different stages of maturation and capacitation.

\section{Classification of fluorescence patterns}

Immunolocalization on fixed preparations does not determine whether the epitopes are localized on the surface of live spermatozoa or exposed mainly in dead cells. Therefore, the distribution of P47 on live and permeabilized cell populations was tested by fluorescence microscopy. The percentage of cells in live cell populations that showed specific fluorescence signals (Fig. 4a) corresponded to the number of intact live cells determined separately by propidium iodide $(77 \%)$. After digitonin permeabilization $100 \%$ of cells were propidium iodide-positive, as determined separately), no cells with P47-specific fluorescence were found, probably due to the loss of the plasma membrane as a consequence of digitonin treatment. In untreated sperm populations, spermatozoa stained with Hoechst 33258 (that is, spermatozoa with damaged plasma membrane) were P47-negative. In contrast, only unstained live spermatozoa showed the specific P47 fluorescence patterns (Fig. 4b,c), indicating that P47 is associated with the plasma membrane of spermatozoa.

As fluorescence patterns were shown to be identical in live and fixed sperm preparations, further studies were performed after fixation to determine the time course of the stage-dependent changes of the P47 localization.

In spermatozoa, two main fluorescence patterns were observed: (1) the fluorescence signal covering the entire acrosomal region (designated as A, Fig. 5a) and (2) the fluorescence signal at the apical ridge of the sperm head (designated as P, Fig. 5b,c). The fluorescence signals at the apical ridge were classified into three intensity levels: p1 (faint), p2 (moderate) and p3 (intense) to quantify the distribution of patterns and the changes in the distribution of patterns. The fluorescence was specific as shown by replacement of anti-MGP 53/57 antibody with pre-immune preparation and the use of pre-absorbed antibody.

\section{Changes in P47 localization during epididymal maturation}

Most spermatozoa (about 80\%) leaving the testis showed one of the fluorescence patterns of the apical ridge ( 1 1, p2 or $\mathrm{p} 3)$. The distribution of intensities shifted to the most strong fluorescence in the apical ridge (p3) as spermatozoa proceeded from caput to cauda epididymides (Fig. 6a). However, P47 remained strictly localized at the apical ridge in more than $80 \%$ of the cells. The observation of Ensslin et al. (1998) that P47 appears to cover the entire acrosomal membrane when passing the duct could not be confirmed statistically. The percentage of spermatozoa with acrosomal fluorescence (3.7 versus $2.3 \%$ of pattern A) remained unchanged.

Concomitantly, the P47 band at $47 \mathrm{kDa}$ was detected in sperm extracts of each epididymal region by electrophoresis and western blot analysis (Fig. 6b, lanes 1-3).

\section{Changes in P47 localization during in vitro capacitation}

The same two patterns were observed in ejaculated spermatozoa, with almost identical quantitative pattern distribution. Under capacitation treatment over a period of $3 \mathrm{~h}$, the percentage of spermatozoa of both functional state (ejaculated and epididymal spermatozoa) with fluorescence in the apical ridge (p1, p2 and p3) decreased over time. The percentage of spermatozoa expressing fluorescence over the entire acrosomal region (pattern A) or without any fluorescence signal (p0) increased. However, there were noticeable differences in the localization and intensity of P47 signals in the apical ridge during capacitation treatment between epididymal and ejaculated spermatozoa $(P<0.08)$, as well as a significant influence of incubation time on percentages of spermatozoa showing apical or acrosomal patterns $(P<0.05)$. There was a significant interaction of the origin of spermatozoa and treatment influence $(P<0.05)$. Therefore, the changes of distribution were analysed for epididymal and ejaculated spermatozoa 

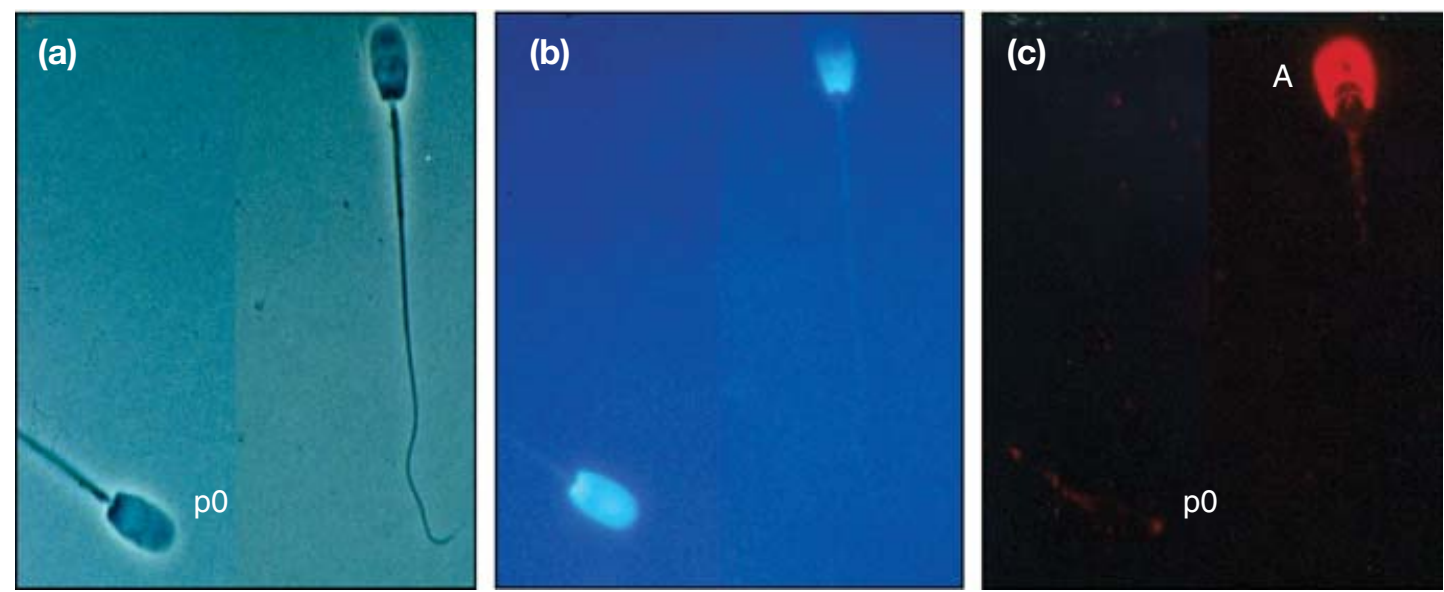

Fig. 4. Localization of pig lactadherin P47 on live spermatozoa. (a) Phase-contrast photograph. (b) Hoechst-stained spermatozoa: top, spermatozoa stained in the post-equatorial segment, corresponding to live, membrane-intact spermatozoa; bottom, intensively stained spermatozoa, corresponding to spermatozoa with defective membrane. (c) Immunocytochemistry with anti-BT MGP 53/57, fluorescence in the entire acrosomal region (pattern A) observed in membrane-intact spermatozoa, no fluorescence $(\mathrm{p} 0)$ in spermatozoa with defective membrane.
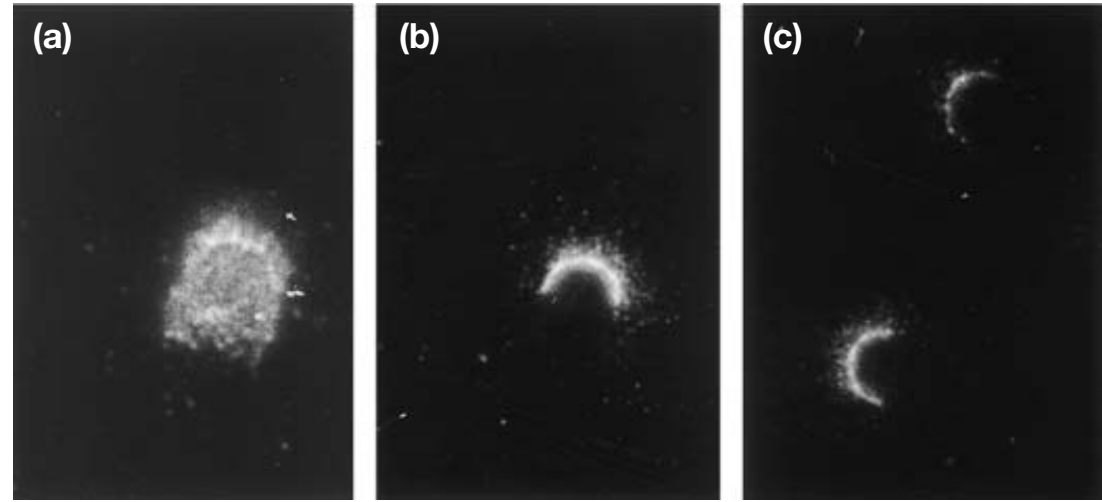

Fig. 5. Immunocytochemical localization of pig lactadherin P47 on spermatozoa. Classification of the fluorescence patterns: (a) pattern A, fluorescence in the entire acrosomal region; (b) pattern $\mathrm{P}$, fluorescence in the apical ridge, intensity p3 (intense); and (c) pattern $\mathrm{P}$, intensities moderate (p2, bottom) and faint (p1, top).

separately (Fig. 7). Within the group of epididymal spermatozoa, there was a significant decrease in spermatozoa with specific fluorescence in the apical ridge (from 92.3 to $51 \% ; P<0.0002$ ), accompanied by changes in the distribution of intensities p1, p2 and p3: the percentage of spermatozoa showing the strongest intensity decreased significantly, and after $3 \mathrm{~h}$ of incubation spermatozoa showing the faint intensity (p1) were missing. Concomitantly, a significant increase in spermatozoa with fluorescence over the entire acrosomal region (pattern $A$, from 1.3 to $17.7 \% ; P<0.01$ ) as well as a significant increase in non-stained spermatozoa ( $\mathrm{p} 0$, from $5.0 \%$ after $3 \mathrm{~min}$ to $31.3 \%$ after $3 \mathrm{~h}$ incubation) was observed. These findings were paralleled by the observation that the intensity of the protein band at $47 \mathrm{kDa}$ in western blots of the sperm extracts was markedly reduced after a $3 \mathrm{~h}$ treatment when compared with shorter incubation periods (Fig. 6b, lane 7, compared with lanes 5 and 6).

There was a similar decline in the total percentage of ejaculated spermatozoa showing specific fluorescence signal in the apical ridge $(P<0.03)$, although to a lower degree than in epididymal spermatozoa (to $75.7 \%$ ). The tendency in re-distribution of fluorescence patterns $\mathrm{p} 1$, p2, p3 was similar, but not statistically significant. In addition, the tendency in the increase of spermatozoa showing fluorescence over the entire acrosomal region was not significant.

Data were fitted to two kinetic models to confirm that the changes in P47 fluorescence patterns obey the different temporal dependence in epididymal and ejaculated sperm populations (Fig. 8). The changes in the ejaculated spermatozoa could be described by a linear model $(P<0.05)$, and the changes in epididymal 
(a)

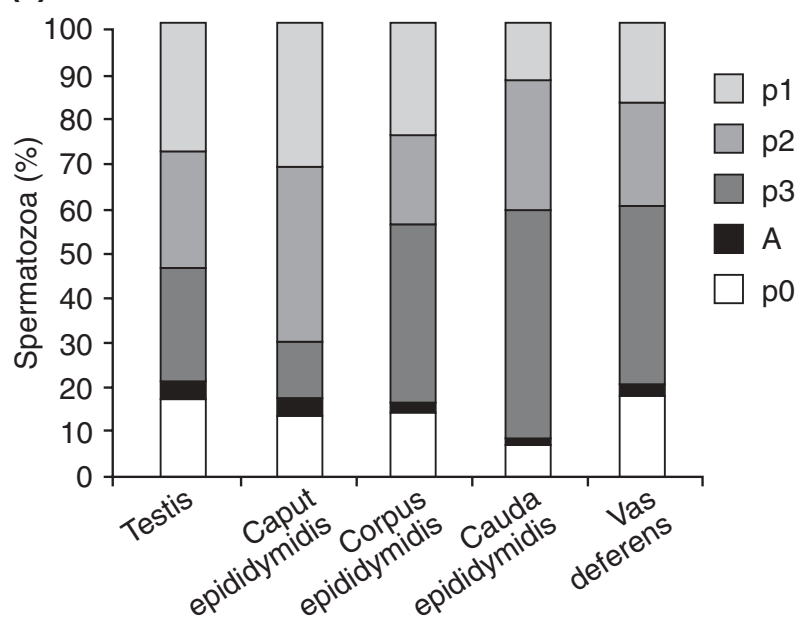

(b)

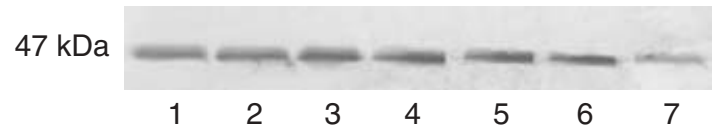

Fig. 6. Localization of pig lactadherin P47 during passage through the male genital tract. (a) Distribution of patterns during the duct passage $(n=3$; percentages): testis: $\mathrm{p} 1=29.3 \pm 15.6$, $\mathrm{p} 2=26.0 \pm 8.6 ; \mathrm{p} 3=25.3 \pm 13.1 ; \mathrm{A}=4.3 \pm 2.3 ; \mathrm{p} 0=15.0 \pm 8.3 ;$ caput epididymidis: $\mathrm{p} 1=32.0 \pm 11.9, \mathrm{p} 2=40.0 \pm 12.5 ; \mathrm{p} 3=$ $12.0 \pm 5.5 ; \mathrm{A}=3.7 \pm 1.8 ; \mathrm{p} 0=11.3 \pm 7.7 ;$ corpus epididymidis: $\mathrm{p} 1=25.7 \pm 18.2, \quad \mathrm{p} 2=19.7 \pm 9.1 ; \quad \mathrm{p} 3=40.3 \pm 19.9 ; \quad \mathrm{A}=2.3 \pm$ $1.9 ; \mathrm{p} 0=12.0 \pm 9.5$; cauda epididymidis: $\mathrm{p} 1=12.7 \pm 2.8$, $\mathrm{p} 2=$ $29.0 \pm 2.6 ; \mathrm{p} 3=50.7 \pm 3.8 ; \mathrm{A}=1.3 \pm 1.3 ; \mathrm{p} 0=5.0 \pm 1.5 ;$ and vas deferens: $\mathrm{p} 1=18.3 \pm 9.9, \mathrm{p} 2=23.0 \pm 6.1 ; \mathrm{p} 3=40.0 \pm 16.8$; $\mathrm{A}=2.3 \pm 1.9 ; \mathrm{p} 0=16.3 \pm 10.8$. $\mathrm{p} 1$, faint intensity; $\mathrm{p} 2$, moderate intensity; p3, intense; pattern $\mathrm{A}$, fluorescence in the entire acrosomal region; p0, no fluorescence. (b) Detection of lactadherin in sperm extracts. (1) Caput spermatozoa; (2) corpus spermatozoa; (3) cauda spermatozoa; (4) 1/2 h capacitated cauda spermatozoa; (5) $1 \mathrm{~h}$ capacitated cauda spermatozoa; (6) $2 \mathrm{~h}$ capacitated cauda spermatozoa; and (7) 3 h capacitated cauda spermatozoa.

spermatozoa by a polynomial model $(P<0.05)$. The number of stained cells was not only lower in epididymal spermatozoa than in ejaculated spermatozoa after $3 \mathrm{~h}$ incubation, but also the changes in epididymal spermatozoa in the second half of the incubation were more rapid than in ejaculated spermatozoa, as shown by derivative of model function (Fig. 8).

The sperm samples from three boars were treated with LPC after incubation in capacitation medium for $3 \mathrm{~h}$ to examine whether the increase in fluorescence signal over the entire acrosomal region was characteristic for capacitating spermatozoa. The percentage of spermatozoa with different patterns of P47 fluorescence was determined by simultaneous evaluation of the acrosomal state. After stimulation of the acrosome reaction, the percentage of spermatozoa showing pattern A decreased rapidly (from 12 to $4 \%$ ). The percentage of spermatozoa with fluorescence in the apical ridge decreased in patterns p3 and p2 (from 28\% in each class to 11 and $12 \%$, respectively). The percentage of spermatozoa with pattern p1 increased from 27 to $38 \%$, whereas the intensity of this pattern became merely distinguishable after LPC treatment. The percentage of spermatozoa without fluorescence signal progressed from 6 to $34 \%$. The spermatozoa with fluorescence signal were identified as acrosome-intact by phase-contrast microscopy after LPC treatment.

\section{Discussion}

Lactadherin-like proteins have been identified in the male genital tracts of pigs, cattle, mice, humans (Ensslin et al., 1998) and horses (E. Töpfer-Petersen and M. Gentzel, unpublished). The wide distribution of messenger RNA coding for lactadherin P47 (testis, epididymis, mammary gland, uterus, adrenal gland, tonsil, muscle, heart, lymphatic gland, thymus and kidney) indicates that their action is not restricted to the particular tissue (Ensslin et al., 1998). These results are in agreement with those of Andersen et al. (1997) who demonstrated that homologous bovine milk fat globule membrane lactadherins (formerly PAS 6/7 and MGP 53/57) are expressed in a number of tissues essentially similar to those detected by Ensslin et al. (1998).

As the sequence identity is about $80 \%$ between cow and pig lactadherins, a polyclonal antibody directed against purified bovine MGP 53/57 showed strong crossreactivity with the members of the lactadherin family in pigs. Lactadherin P47 was identified by immunological approaches in testis and in all parts of the epididymis in pigs. The epithelial cells stained positive for the protein in the epididymis, whereas in the testis the protein was found to be associated solely with late germ cells, indicating that spermatozoa released into the lumen and transported into the epididymis already carry P47 molecules on the surface. P47 was localized in the plasma membrane over the apical ridge in most spermatozoa of testicular origin. A small portion showed P47 at the entire acrosomal region. These results confirm the findings of Ensslin et al. (1998). In the present study, however, P47 localization during epididymal maturation and in vitro capacitation was studied by quantifying the intensity and distribution patterns.

Interpreting the data (low amount of protein on the testicular sperm surface and in the testicular sperm extracts), P47 appears to be already associated with the peri-acrosomal plasma membrane when leaving the testis, possibly being masked by testicular proteins. It can be hypothesized that the strong interaction of P47 with the sperm membrane is mediated by the C-terminal peptide of the C2-like domain that is homologous to the phosphatidylserin-binding region of factor VIII (Gilbert and Baleja, 1995) and is highly conserved within the lactadherin family (Andersen et al., 2000). 
(a)

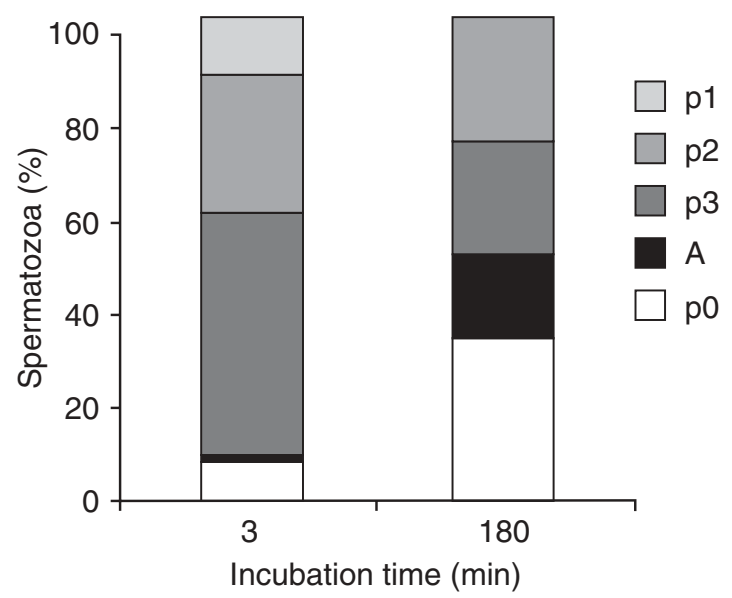

(b)

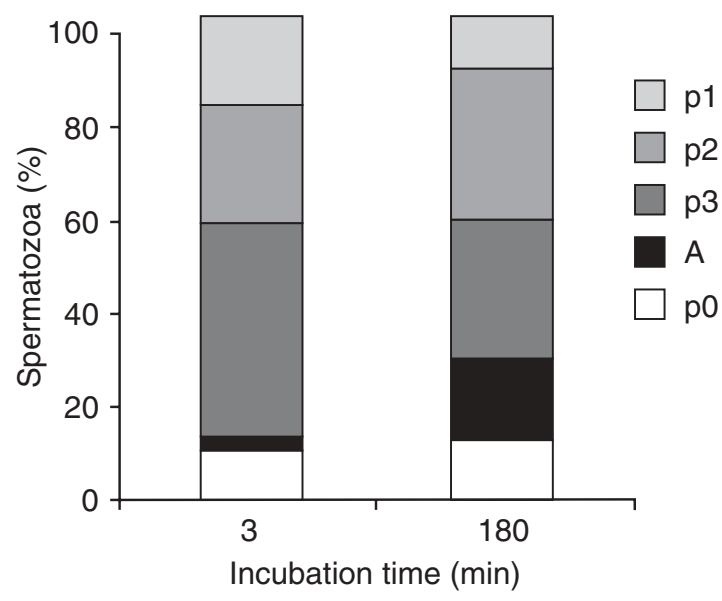

Fig. 7. Localization of pig lactadherin P47; redistribution of patterns during in vitro capacitation treatment. (a) Epididymal spermatozoa after 3 and 180 min of incubation under capacitating conditions ( $n=3$; percentages): 3 min, p1 $=12.7 \pm$ $2.8, \mathrm{p} 2=29.0 \pm 2.6 ; \mathrm{p} 3=50.7 \pm 3.8 ; \mathrm{A}=1.3 \pm 1.3 ; \mathrm{p} 0=5.0 \pm 1.5 ; 180 \mathrm{~min}, \mathrm{p} 1=0.0 \pm 0.0, \mathrm{p} 2=27.0 \pm 3.8 ; \mathrm{p} 3=24.0 \pm$ 4.4; $\mathrm{A}=17.7 \pm 1.9 ; \mathrm{p} 0=31.3 \pm 8.9$. (b) Ejaculated spermatozoa after 3 and $180 \mathrm{~min}$ of incubation under capacitating conditions $(n=3): 3 \mathrm{~min}, \mathrm{p} 1=21.3 \pm 12.4, \mathrm{p} 2=25.7 \pm 4.3 ; \mathrm{p} 3=47.7 \pm 15.3 ; \mathrm{A}=3.3 \pm 1.3 ; \mathrm{p} 0=4.0 \pm 3.5 ; 180 \mathrm{~min}$ $\mathrm{p} 1=12.7 \pm 11.2, \mathrm{p} 2=32.7 \pm 5.4 ; \mathrm{p} 3=30.3 \pm 4.8 ; \mathrm{A}=18 \pm 6.9 ; \mathrm{p} 0=6.3 \pm 3.8$. p1, faint intensity; $\mathrm{p} 2$, moderate intensity; $\mathrm{p} 3$, intense; pattern $A$, fluorescence in the entire acrosomal region; p0, no fluorescence.

The increase in signal intensity at the apical region of the sperm head during epididymal transit may be caused by the unmasking of the protein already present on testicular spermatozoa, or by interaction of the protein secreted by the epididymis with the spermatozoa (subsequent association of P47 with the sperm surface), possibly as the result of a changing lipid architecture in the apical membrane domain (Töpfer-Petersen et al., 1990a,b; Christova et al., 2002). An opposite dynamic of changes on the sperm surface was observed in both epididymal and ejaculated sperm populations during capacitation. A shift of the P47 signal to the entire acrosomal distribution occurred and this was accompanied by an increase in a cell portion showing no fluorescence. Whereas P47 loss is related to acrosome reaction occurring at the end of in vitro capacitation, the acrosomal appearance of the protein can be due to the combined effects of unmasking by the release of coating proteins and the migration of P47 molecules from the apical subdomain into the acrosomal domain. The apical head plasma membrane in pigs seems to form a specialized subdomain. Gadella and Harrison (2002) demonstrated in boar spermatozoa the exposure of aminophospholipids and the subsequent migration of cholesterol into the apical plasma membrane as the result of bicarbonate-induced lipid re-organization under conditions that promote capacitation. The migration of the transmembrane proteins P86/5 into the apical subdomain may be closely related to these processes (Aguas and Pinto DaSilva, 1989; Töpfer-Petersen et al., $1990 a, b)$. The abolition of the barrier may also allow

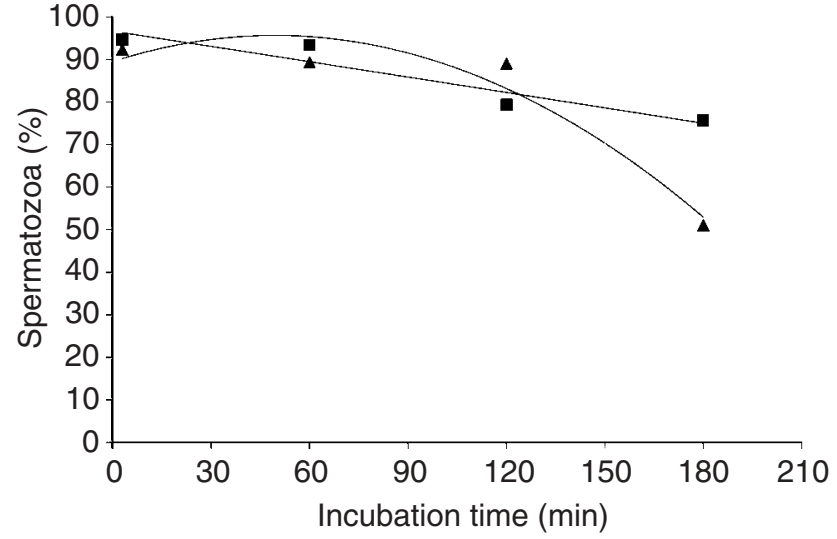

Fig. 8. Kinetics of loss of the signal in the apical ridge in ejaculated $(\mathrm{Ej})$ and $(\boldsymbol{\Lambda})$ epididymal (Ep) spermatozoa in pigs. The following kinetic models describe the temporal changes:

$\mathrm{Ep}=-0.0025 t^{2}+0.25 t+89.5 ; R^{2}=0.93$

$\mathrm{Ej}=-0.12 t+96.7 ; R^{2}=0.91$

Changes in epidydimal spermatozoa progress more rapidly than in ejaculated spermatozoa in the second half of incubation:

$d(E p) / d t=-0.005 t+0.25$

$d(E j) / d t=-0.12$

$|d(E p) / d t|>|d(E j) / d t|$ when $t>74 \min$.

the migration of lipid-bound proteins from the apical subdomain into the acrosomal region.

It appears important that the kinetics of signal loss or shift differed for epididymal and ejaculated spermatozoa. The rate of signal changes was lower in ejaculated 
spermatozoa (threefold at the beginning of the third hour of incubation: $\Delta s /\left.\Delta t\right|_{t=3}=-0.12$ in ejaculated spermatozoa against -0.36 in epididymal spermatozoa), providing evidence for accelerated capacitation-induced membrane remodelling in epididymal spermatozoa. It is unlikely that these kinetics are related solely to the incompletely matured morphology of epididymal spermatozoa. Indeed, the subpopulation differences in response to bicarbonate, caused by variable efficiencies in epididymal maturation within a sperm population as judged by cell morphology, have been reported by Flesch et al. (2001). Only spermatozoa that have accomplished the process of morphological maturation respond to bicarbonate by positive merocyanine staining, indicating the occurrence of cholesterol efflux from the sperm membrane initiating the capacitation process. Therefore, a lower response to capacitating conditions in epididymal spermatozoa would be expected than in ejaculated spermatozoa if the degree of epididymal maturation plays a crucial role. It appears more likely that in the present study such differences were caused by completion of the surface coat at the time of ejaculation. Epididymal spermatozoa that did not have contact with fluids of accessory glands seemed to be able to undergo capacitation-related loss of signal in the apical ridge at a higher rate, as shown by the observed kinetics. Similarly, more rapid functional destabilization of the plasma membrane of epididymal spermatozoa during long-term incubation under fertilizing conditions was detected by changes in osmotic behaviour of cell volume in an earlier study (Petrunkina and Töpfer-Petersen, 2000). Epididymal spermatozoa demonstrated rapid aberration in response to osmotic conditions and marked deviation from the model of perfect osmometer at approximately the same time as in the present study, that is, during $3 \mathrm{~h}$ of incubation.

The function of lactadherin in association with spermatozoa is largely unknown. The possible function of boar membrane P47 as an integrin RGD-dependent ligand as suggested by Ensslin et al. (1998) was previously indirectly supported by studies of Andersen et al. (1997), who showed that interaction between bovine lactadherin and integrin $\alpha_{V} \beta_{5}$ was RGD-dependent. Moreover, these investigators have recently determined that lactadherin can act as a link between two surfaces by binding to integrin receptors through its $\mathrm{N}$-terminal RGD-binding sites in the second EGF-like domain and to phospholipids through its C-terminal C1/C2-like domains (Andersen et al., 2000). Taylor et al. (2000) demonstrated that human lactadherin (formerly BA46) expressed in human milk and breast carcinomas promotes RGDdependent cell adhesion via integrins. The proposed hypothesis of active participation in gamete interaction which takes place only after completing the acrosome reaction via the integrin binding site can be ruled out as lactadherin is not present on acrosome-reacted spermatozoa. However, the presentation of lactadherin on spermatozoa entering the oviduct indicates the interaction with integrin receptors localized on the oviductal epithelium (Chegini et al., 2001), thereby regulating cross-talk between spermatozoa and the oviductal epithelium. In addition, the results of the present study give an indication that lactadherin is involved in other aspects of sperm physiology such as capacitation and acrosome reaction, although it cannot be ruled out that the re-localization of the protein occurs as a consequence of these processes. The still unknown molecular mechanisms behind the observed functional changes need to be determined. One possible mechanism is an interaction with the EGF receptor (EGFR, found on the human spermatozoa; Damjanov et al., 1993) to which EGF-like domains such as those at the $\mathrm{N}$-terminus of P47 bind specifically. Members of the EGFR family are transmembrane tyrosine kinases, and are involved in intracellular signalling. The signal transduction pathways that induce changes in the migration and unmasking of lactadherin epitopes require further investigation. Further study is also required to determine whether lactadherin epitopes are triggered or integrated in a further signal cascade priming acrosome reaction and preparation of sperm-egg fusion.

\section{References}

Aguas AP and Pinto da Silva P (1989) Bimodal redistribution of surface transmembrane glycoproteins during $\mathrm{Ca}^{2+}$-dependent secretion (acrosome reaction) in boar spermatozoa Journal of Cell Science 93 467-479

Andersen MH, Berglund JT, Rasmussen JT and Petersen TE (1997) Bovine PAS $6 / 7$ binds $\alpha_{v} \beta_{5}$ integrin and ionic phospholipids through two domains Biochemistry 36 5441-5446

Andersen MH, Graversen H, Fedosov SN, Petersen TE and Rasmussen JT (2000) Functional analyses of two cellular binding domains of bovine lactadherin Biochemistry 39 6200-6206

Aoki N, Ujita M, Kuroda H, Urabe M, Noda A, Adachil T, Nakamura R and Matsuda T (1994) Immunologically cross-reactive $57 \mathrm{kDa}$ and 53 kDa glycoprotein antigens of bovine milk fat globule membrane: isoforms with different $N$-linked sugar chains and differential glycosylation at early stages of lactation Biochemica et Biophysica Acta 1200 227-234

Aoki N, Kishi M, Taniguchi Y, Adachi T, Nakamura R and Matsuda T (1995) Molecular cloning of glycoprotein antigens MGP 57/53 recognized by monoclonal antibodies raised against milk fat globule membrane Biochemica et Biophysica Acta 1245 385-391

Benhoff S (1993) The role of cholesterol during capacitation of human spermatozoa Human Reproduction 8 2001-2008

Blobel CP, Wolfsberg TG, Turck CW, Myles DG, Primakoff P and White JM (1992) A potential fusion peptide and an integrin ligand domain in a protein active in sperm-egg fusion Nature 356 248-252

Chegini N, Kotseos K, Ma C, Williams RS, Diamond MP, Holmdahl L and Skinner K (2001) Differential expression of integrin alpha $v$ and beta 3 in serosal tissue of human intraperitoneal organs and adhesion Fertility and Sterility 75 791-796

Christova Y, James PS, Cooper TG and Jones R (2002) Lipid diffusion in the plasma membrane of mouse spermatozoa: changes during epididymal maturation, effects of $\mathrm{pH}$, osmotic pressure, and knockout of the $c$-ros gene Journal of Andrology 23 384-92

Cooper TG (1992) Epididymal proteins and sperm maturation. In Spermatogenesis-Fertilization-Contraception pp 285-318 Eds E Nieschlag, UF Habenicht and G Stock. Springer Verlag, New York

Damjanov I, Solter D and Knowles BB (1993) Functional epidermal growth factor receptor localizes to the postacrosomal region of human 
spermatozoa Biochemical and Biophysical Research Communications 190 901-906

Ensslin M, Calvete J, Thole HH, Sierralta WD, Adermann K, Sanz L and Töpfer-Petersen E (1995) Identification by affinity chromatography of boar sperm membrane-associated proteins bound to immobilized porcine zona pellucida. Mapping of the phosphorylethanolaminebinding region of spermadhesin AWN Biological Chemistry HoppeSeyler 376 733-738

Ensslin M, Vogel T, Calvete JJ, Thole HH, Schmidtke J, Matsuda T and Töpfer-Petersen E (1998) Molecular cloning and characterization of P47, a novel boar sperm-associated zona pellucida-binding protein homologous to a family of mammalian secretory proteins Biology of Reproduction 58 1057-1064

Flesch FM, Brouwers JF, Nievelstein PF, Verkleij AJ, van Golde LM, Colenbrander B and Gadella BM (2001) Bicarbonate stimulated phospholipid scrambling induces cholesterol redistribution and enables cholesterol depletion in the sperm plasma membrane Journal of Cell Science 114 3543-3555

Gadella BM and Harrison RA (2002) Capacitation induces cyclic adenosine 3', 5'-monophosphate-dependent, but apoptosis-unrelated, exposure of aminophospholipids at the apical head plasma membrane of boar sperm cells Biology of Reproduction 67 340-350

Gilbert GE and Baleja JD (1995) Membrane-binding peptide from the C2 domain of factor VIII forms an amphipathic structure as determined by NMR spectroscopy Biochemistry 34 3022-3031

Harrison RAP and Vickers SE (1990) Use of fluorescent probes to access membrane integrity in mammalian spermatozoa Journal of Reproduction and Fertility 88 343-352

Harrison RAP, Mairet B and Miller NGA (1993) Flow cytometric studies of bicarbonate-mediated $\mathrm{Ca}^{2+}$ influx in boar sperm populations Molecular Reproduction and Development 35 197-208

Hunter RH (1996) Ovarian control of very low sperm/egg ratios at the commencement of mammalian fertilization to avoid polyspermy Molecular Reproduction and Development 44 417-422

Hunter RH (2001) Histophysiology of the Fallopian tubes in relation to sperm binding, release and completion of capacitation Italian Journal of Anatomy and Embryology 106 Supplement 2 279-289

Kirchhoff C and Hale G (1996) Cell-to-cell transfer of glycosylphosphatidylinositol-anchored membrane proteins during sperm maturation Molecular Human Reproduction 2 177-184

Krause D (1966) Untersuchungen am Bullensperma unter Berücksichtigung der fertilitätsdiagnostischen Bedeutung der Befunde Habilitationsschrift, Tierärztliche Hochschule, Hannover

Laemmli UK (1970) Cleavage of structural proteins during the assembly of the head of bacteriophage T4 Nature 227 680-685

Larocca D, Peterson JA, Urrea R, Kuniyoshi R, Bistrain AM and Ceriani RL (1991) A Mr 46,000 human milk fat globule protein that is highly expressed in human breast tumors contains factor VIII-like domains Cancer Research $\mathbf{5 1}$ 4994-4998

Mather IH (2000) A review and proposed nomenclature for major proteins of the milk-fat globule membrane Journal of Dairy Science 83 203-247
Peterson JA, Scallan CD, Ceriani RL and Hamosh M (2001) Structural and functional aspects of three major glycoproteins of the human milk fat globule membrane Advances in Experimental Medicine and Biology 501 179-187

Petrunkina AM and Töpfer-Petersen E (2000) Heterogeneous osmotic behaviour in boar sperm populations and its relevance for detection of changes in plasma membrane Reproduction, Fertility and Development 12 297-305

Petrunkina AM, Gehlhaar R, Drommer W, Waberski D and Töpfer-Petersen E (2001) Selective sperm binding to pig oviductal epithelium in vitro. Reproduction 121 889-896

Shur BD (1998) Is sperm galactosyltransferase a signaling subunit of a multimeric gamete receptor? Biochemical and Biophysical Research Communications 250 537-543

Snell WJ and White JM (1996) The molecules of fertilization Cell 85 629-637

Suarez SS (1999) Regulation of sperm transport in the mammalian oviduct. In The Male Gamete: from Basic Science to Clinical Applications pp 71-80 Ed. C Gagnon. Cache River Press, Illinois

Taylor MR, Couto JR, Scallan CD, Ceriani RL and Peterson JA (2000) Lactadherin (formerly BA46), a membrane-associated glycoprotein expressed in human milk and breast carcinomas, promotes Arg-Gly-Asp (RGD)-dependent cell adhesion DNA Cell Biology 16 861-869

Töpfer-Petersen $\mathbf{E}$ (1999) Carbohydrate-based interactions on the route of a spermatozoon to fertilization Human Reproduction 5 314-329

Töpfer-Petersen E, Cechova D, Henschen A, Steinberger M, Friess AE and Zucker A (1990a) Cell biology of acrosomal proteins Andrologia 1 $110-121$

Töpfer-Petersen E, Friess AE, Stoffel M and Schill WB (1990b) Boar sperm membranes antigens. II. Reorganization of an integral membrane antigen during capacitation and acrosome reaction Histochemistry 93 490-495

Töpfer-Petersen E, Calvete JJ, Sanz L and Sinowatz F (1995) Carbohydrateand heparin-binding proteins in mammalian fertilization Andrologia $\mathbf{2 7}$ 303-324

Töpfer-Petersen E, Romero A, Varela PF, Ekhlasi-Hundrieser M, Dostalova Z, Sanz L and Calvete JJ (1998) Spermadhesins: a new protein family. Facts, hypothesis and perspectives Andrologia 30 217-224

Töpfer-Petersen E, Wagner A, Friedrich J, Petrunkina A, Ekhlasi-Hundrieser M, Waberski D and Drommer W (2002) Function of the mammalian oviductal sperm reservoir Journal of Experimental Zoology 292 210-215

Yanagimachi R (1994) Mammalian fertilization. In The Physiology of Reproduction pp 189-317 Eds E Knobil and JD Neill. Raven Press, New York

Received 22 July 2002.

First decision 9 September 2002.

Revised manuscript received 17 September 2002.

Accepted 5 November 2002. 